\title{
Tropospheric and total ozone columns over Paris (France) measured using medium-resolution ground-based solar-absorption Fourier-transform infrared spectroscopy
}

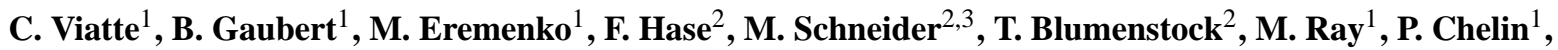 \\ J.-M. Flaud ${ }^{1}$, and J. Orphal ${ }^{2}$ \\ ${ }^{1}$ Laboratoire Interuniversitaire des Systèmes Atmosphériques (LISA), UMR7583, CNRS, \\ Université Paris-Est Créteil et Université Paris Diderot, Institut Pierre Simon Laplace, 94010 Créteil, France \\ ${ }^{2}$ Institute for Meteorology and Climate Research (IMK), Karlsruhe Institute of Technology (KIT), Karlsruhe, Germany \\ ${ }^{3}$ Centro de Investigación Atmosférica de Izaña, Agencia Estatal de Meteorología (AEMET), Spain
}

Received: 24 May 2011 - Published in Atmos. Meas. Tech. Discuss.: 31 May 2011

Revised: 8 September 2011 - Accepted: 17 October 2011 - Published: 25 October 2011

\begin{abstract}
Ground-based Fourier-transform infrared (FTIR) solar absorption spectroscopy is a powerful remote sensing technique providing information on the vertical distribution of various atmospheric constituents. This work presents the first evaluation of a mid-resolution ground-based FTIR to measure tropospheric ozone, independently of stratospheric ozone. This is demonstrated using a new atmospheric observatory (named OASIS for "Observations of the Atmosphere by Solar absorption Infrared Spectroscopy"), installed in Créteil (France). The capacity of the technique to separate stratospheric and tropospheric ozone is demonstrated. Daily mean tropospheric ozone columns derived from the Infrared Atmospheric Sounding Interferometer (IASI) and from OASIS measurements are compared for summer 2009 and a good agreement of $-5.6( \pm 16.1) \%$ is observed. Also, a qualitative comparison between in-situ surface ozone measurements and OASIS data reveals OASIS's capacity to monitor seasonal tropospheric ozone variations, as well as ozone pollution episodes in summer 2009 around Paris. Two extreme pollution events are identified (on the 1 July and 6 August 2009) for which ozone partial columns from OASIS and predictions from a regional air-quality model (CHIMERE) are compared following strict criteria of temporal and spatial coincidence. An average bias of $0.2 \%$, a mean
\end{abstract}

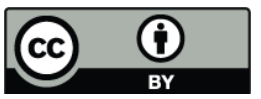

Correspondence to: C. Viatte (camille.viatte@lisa.u-pec.fr) square error deviation of $7.6 \%$, and a correlation coefficient of 0.91 is found between CHIMERE and OASIS, demonstrating the potential of a mid-resolution FTIR instrument in ground-based solar absorption geometry for tropospheric ozone monitoring.

\section{Introduction}

Ozone is a key species in the Earth's atmosphere. In the stratosphere, its presence is vital for life on Earth because it absorbs harmful ultraviolet radiation; in the troposphere, it plays an important role in photochemical processes. It is also an important greenhouse gas and is considered to be a major air pollutant affecting ecosystems and human health. Therefore, monitoring of tropospheric ozone is an important part of climate and air quality research, in order to reduce uncertainties on radiative forcing of climate change and atmospheric composition change (IPCC, 2007). Assessment of long-term trends in tropospheric ozone is difficult due to the scarcity of representative observing sites with long records (IPCC, 2007). For instance, limited spatial and temporal coverage of ozone sondes, and in situ surface measurements, do not provide a sufficient tropospheric ozone data set. However, a few remote sensing techniques are now able to monitor tropospheric ozone, such as ground based high-resolution FTIR (Pougatchev et al., 1996; Schneider et al., 2005), LIDAR (Beekmann et al., 1995), and FTIR onboard satellite

Published by Copernicus Publications on behalf of the European Geosciences Union. 
(Keim et al., 2009; Dufour et al., 2010). For this purpose, we have assessed the capability of mid-resolution FTIR solar absorption spectroscopy for monitoring tropospheric ozone, using a new atmospheric observatory that has been installed in 2008 in Créteil near Paris (France). This new observatory, named OASIS (for "Observations of the Atmosphere by Solar absorption Infrared Spectroscopy"), is equipped by a mid-resolution Fourier-transform infrared spectrometer which measures solar absorption spectra in quasi full automatic mode over the entire year. In general, high-resolution FTIR solar absorption spectroscopy allows monitoring of many atmospheric species (such as ozone), with total column measurements that are well suited for satellite validation (in contrast to in-situ measurements). A medium-resolution and low-throughput FTIR is generally less sensitive since spectral resolution and noise limit the vertical resolution and accuracy of the retrievals (Rodgers, 2000). However such instruments are considerably cheaper and more mobile. It is therefore important to assess their performance. Furthermore, the infrastructure that is required to install such medium-resolution FTIR is less demanding. Finally, many high-resolution FTIR for atmospheric measurements are installed in high altitudes (e.g. Izaña, Jungfraujoch, Zugspitze, Table Mountain ...) and/or remote places far away from sources of air pollution so that measurements of tropospheric ozone are limited with these installations.

In the following chapters, we present the new instrumental set-up installed in Créteil and the methodology to retrieve atmospheric ozone concentrations from solar absorption spectra. Then, we discuss the separation of tropospheric and stratospheric columns based on the information content analysis. For validation, we present comparisons of OASIS tropospheric ozone columns with IASI data (for the 2009 summer period) and with ground-based in-situ measurements (AirParif surface network). Finally, OASIS tropospheric ozone columns are compared with simulations from an atmospheric regional chemistry model (CHIMERE) for two extreme pollution events that occurred in summer 2009 around Paris.

\section{FTIR observations of tropospheric ozone over Créteil (near Paris, France)}

\subsection{Technical description of the new FTIR observatory: OASIS}

OASIS ("Observations of the Atmosphere by Solar absorption Infrared Spectroscopy") is a new ground-based observatory installed in July 2008 on the roof of the Paris-Est University $\left(48.79^{\circ} \mathrm{N}, 2.44^{\circ} \mathrm{E}, 60 \mathrm{~m}\right.$ a.s.l). OASIS can measure infrared atmospheric absorption spectra using the sun as light source and thus monitor continuously the concentrations of important atmospheric constituents, such as ozone.

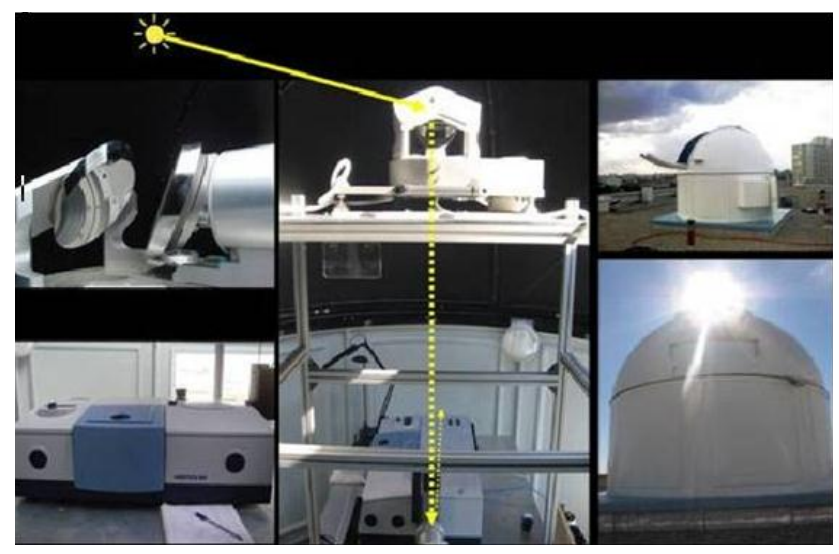

Fig. 1. OASIS observatory: sun tracker (upper-left photo) has two mobiles mirrors which collect and reflect sunlight into the spectrometer (down-left photo) as shown in the middle. In order to protect all these instruments, they are placed into a motorized dome (right photos).

OASIS comprises an automatized dome (Sirius 3.5 "School Model" observatory, $3.25 \mathrm{~m}$ high and $3.5 \mathrm{~m}$ in diameter) in which the upper part, equipped with a mobile aperture, can rotate in order to be aligned with the solar tracker and the sun. Thanks to two operating procedures (astronomical calculation and quadrant detector control), the solar tracker is able to follow the sun during the day. The radiation collected by this sun tracker is focused into the FTIR (Vertex 80, Bruker) which has a maximal resolution of about $0.06 \mathrm{~cm}^{-1}$, using Boxcar apodisation (the maximum optical path difference is $12 \mathrm{~cm}$ ). Using a $\mathrm{KBr}$ beam-splitter and a DTGS (deuterated triglycine sulphate) detector operating at room temperature, the spectral range covered by OASIS is as wide as 600 to $14000 \mathrm{~cm}^{-1}$. The acquisition system was set to perform 30 scans at maximum resolution in order to have one atmospheric spectrum stored every $10 \mathrm{~min}$ in the computer. All these instruments are connected to the same computer in the observatory and are remote-controlled via internet connection. Figure 1 illustrates the OASIS experimental set up.

\subsection{FTIR ozone measurements and analysis}

Ozone concentrations shown in this paper are derived from 1617 measured spectra, corresponding to 75 clear-sky days, from 25 February 2009 to 28 May 2010 at Créteil (France). Atmospheric ozone is retrieved with the PROFFIT 9.6 code (Hase et al., 2004) in a spectral window from 991 to $1073 \mathrm{~cm}^{-1}$ (where the interfering species are $\mathrm{H}_{2} \mathrm{O}, \mathrm{SO}_{2}$, and $\mathrm{NH}_{3}$ ). This code is widely used by the NDACC community to retrieve trace gases from high-resolution FTIR measurements. However it can be adapted and properly used for mid-resolution retrievals. Note that to achieve sufficient information content in the retrievals, the micro-windows 

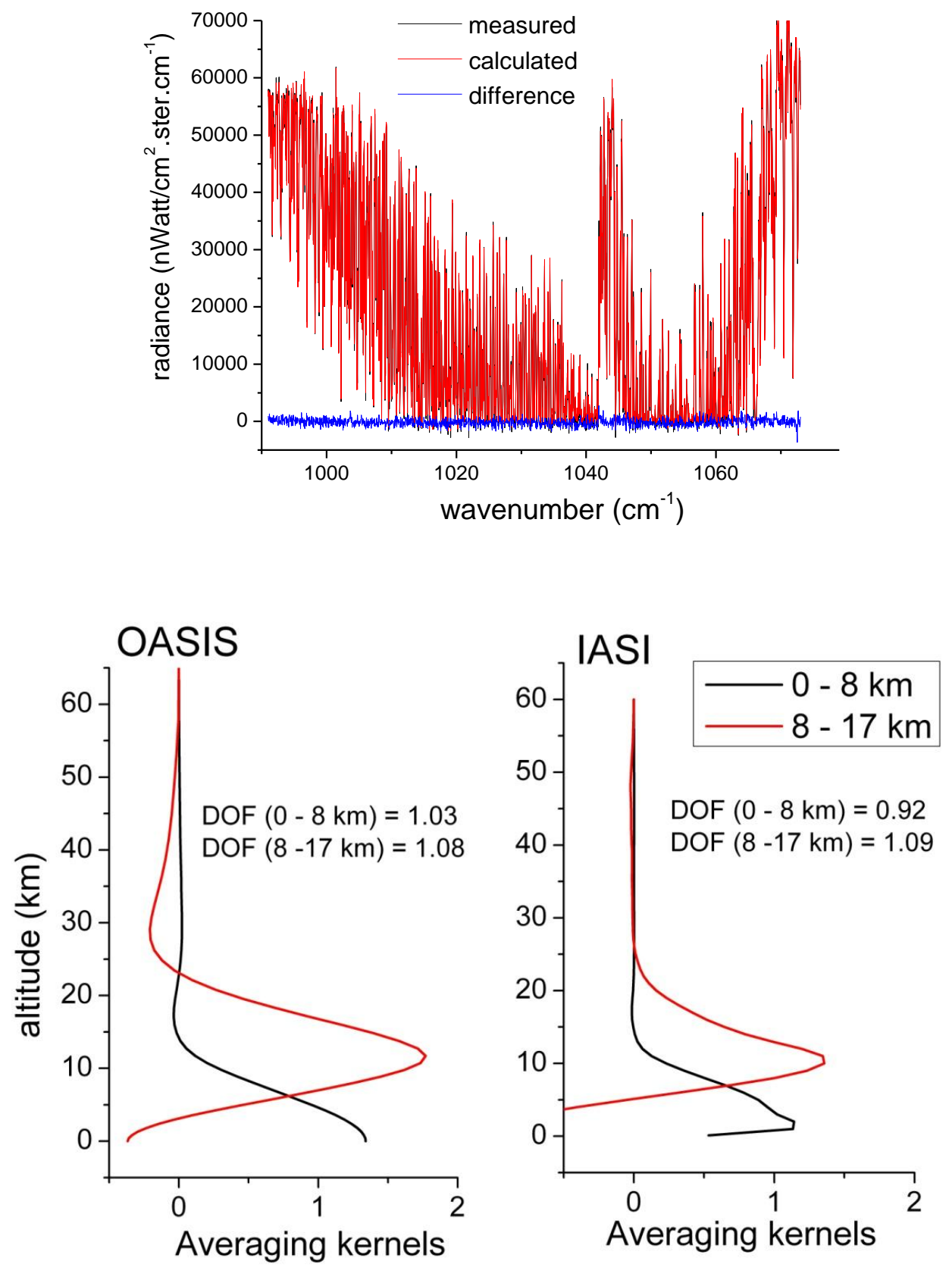

Fig. 2. Upper plot: Example of an atmospheric spectrum recorded with OASIS on 31 March 2009 at 12:58 p.m. (UT), showing the wellknown $\mathrm{O}_{3}$ absorption bands around 10 microns. Black: the measured spectrum. Red: the calculated spectrum. Blue: the difference between the measured and calculated spectra. Lower plot left (right): OASIS (IASI) typical averaging kernels in partial column space from ground to $8 \mathrm{~km}$ and 8 to $17 \mathrm{~km}$ in black and red respectively.

have to be widened compared to high-resolution ozone retrievals. The inversion procedure of such spectra is an ill-posed problem and needs a constrained nonlinear leastsquares fitting technique (Rodgers, 2000). For this purpose, an analytical altitude-dependent regularization method with the regularization matrix containing first and second order Tikhonov constraints (Tikhonov, 1963) was used, together with altitude-dependent coefficients optimized to maximize the information content of the retrievals. The a-priori ozone profile was taken from the mean annual McPeters climatology (McPeters et al., 2008) adapted to the location of the observatory (i.e. between $40^{\circ}$ and $50^{\circ} \mathrm{N}$ ). It is worth noting that all retrievals are performed with the same a-priori data set to ensure that all variability seen in retrieved profiles comes from the measurements. Furthermore, it was observed that the retrieved ozone profiles do not depend on the choice 
of the a-priori profile since a change of a-priori profiles produced negligible differences on the results. Daily temperature and pressure profiles were obtained from the Goddard Space Flight Center (NCEP, National Center for Environment Prediction). For the radiative transfer calculations, all profiles are discretized in 46 levels from ground up to $85 \mathrm{~km}$. The probability distribution function (pdf) of highly variable trace gases is asymmetric. In general the asymmetry is well captured by a log-normal pdf. This is the case for ozone at the tropopause region. Consequently we perform the retrieval on a logarithmic scale in order to assure that the correct a-priori information is employed by the inversion algorithm. In case the variability is small a log-scale retrievals is no disadvantage if compared to a linear retrieval since then the log-normal distribution is very similar to the normal distribution. For more detailed discussion please refer to Hase et al. (2004) and Schneider et al. (2006).

The spectroscopic data were taken from the HITRAN 2004 data base (Rothman et al., 2005). Figure 2 (upper plot) shows a measured spectrum, the corresponding simulated spectrum and the difference between observation and simulation.

Retrievals are characterized by the averaging kernel matrix which represents their sensitivity to the true atmospheric state, and also by the Degrees Of Freedom (DOF) which are the trace of this matrix (Rodgers, 2000). DOF of considered atmospheric layers reach unity when the retrieval contains sufficient information to consider the partial column quasi-independently from others. Figure 2 (lower plot, left) shows typical averaging kernels of OASIS retrievals. From the ground up to $8 \mathrm{~km}$ (black curve) and from 8 to $17 \mathrm{~km}$ (red curve), the DOF reach 1.03 and 1.08 respectively, showing that these two partial columns can be separated. Typical degrees of freedom obtained through OASIS retrievals reach at least 3, which is less than for a high resolution system where DOF are around 4 (Vigouroux et al., 2008; Schneider et al., 2008). Figure 2 (lower plot, right) shows typical averaging kernels of IASI retrievals which apply to the tropospheric and stratospheric partial columns where the DOF reach 0.92 and 1.09 respectively. Compared to OASIS, IASI vertical sensitivity is stronger around $20 \mathrm{~km}$ region because it measures thermal infrared radiation emitted by the Earth's surface and the atmosphere in Nadir geometry, whereas OASIS measurements are performed in solar absorption geometry. Furthermore, IASI retrievals are slightly less sensitive to tropospheric ozone compared to OASIS given values of DOF in the troposphere (0.92 compared to 1.03 ).

To validate the separation of tropospheric and stratospheric ozone columns, we compared stratospheric and tropospheric ozone column time series and evaluated the correlation between these two partials columns (Fig. 3). Total uncertainties of tropospheric ozone, including statistical, systematical and smoothing errors, are estimated to be about 13 to $15 \%$ (depending on the solar elevation angle and the meteorological conditions), while the uncertainty of
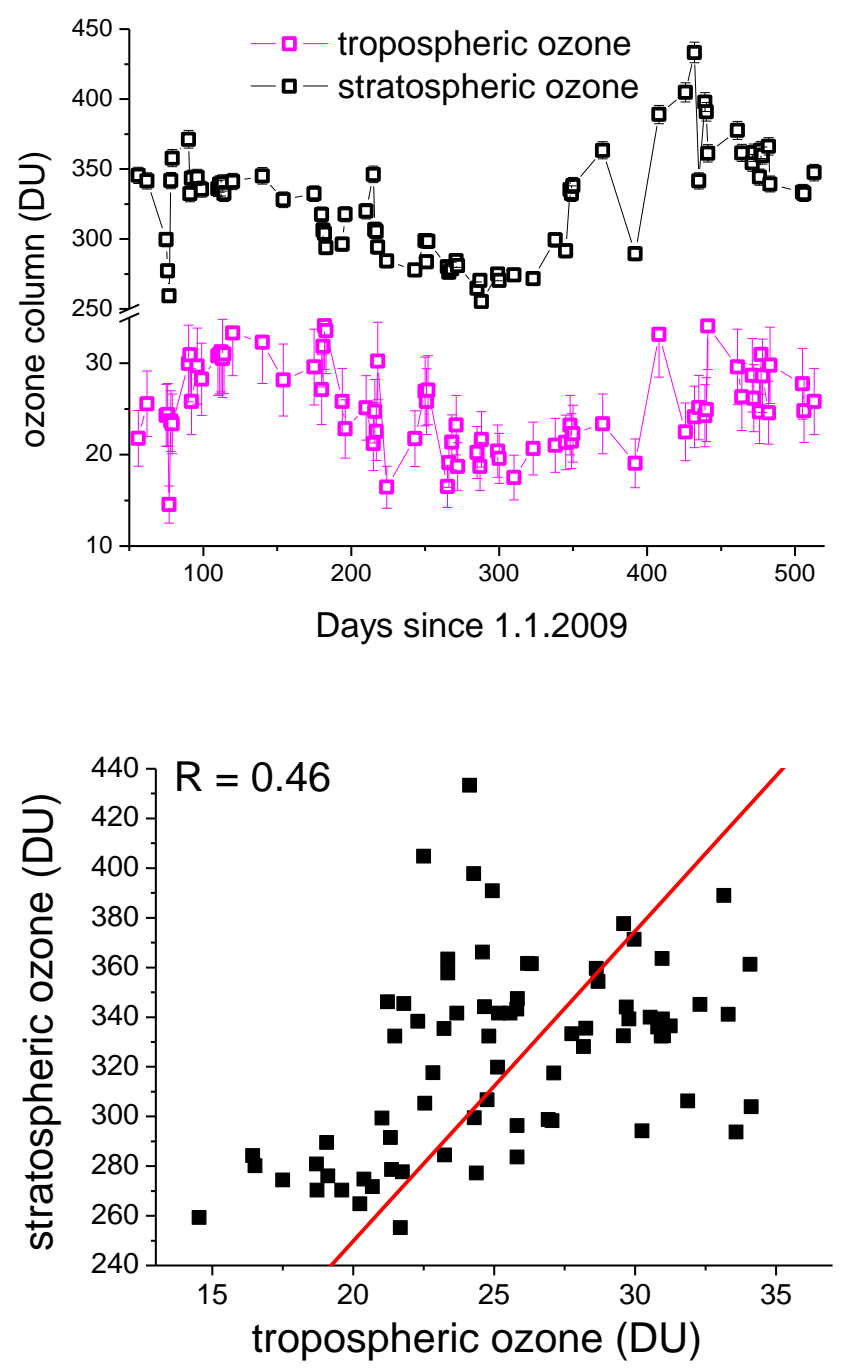

Fig. 3. Upper plot: times series of tropospheric (pink symbols) and stratospheric (black symbols) ozone columns derived from OASIS measurements from 25 February 2009 to 28 May 2010 at Créteil (France). Lower plot: stratospheric ozone related to tropospheric ozone derived from OASIS spectra. The red line is a linear fit with zero intercept.

the stratospheric ozone column is estimated to be around $3 \%$. In Fig. 3, one can see that stratospheric (black symbols) and tropospheric (pink symbols) ozone time series do not present the same structures and that a correlation coefficient of 0.46 is observed. This correlation can be attributed both to the retrieval and to atmospheric dynamical processes occurring around the tropopause region (Holton et al., 1995). Indeed, the averaging kernels, which reflect the vertical sensitivity of the retrievals, show that the retrieved tropospheric amounts have a small stratospheric contribution, and viceversa (Fig. 2). Furthermore, one can note that, two episodes of extreme ozone events, due to meteorological conditions, were observed during this measurement period (days 77 and 
392), for which stratospheric and troposphere ozone concentrations are correlated. In general, the low correlation confirms that OASIS tropospheric and stratospheric ozone amounts are highly independent and can therefore be monitored separately. In addition, the resolving capability as documented by the Averaging kernels (AKs) is affirmed by the fact that we see no significant correlation between the ozone values retrieved for the troposphere and the stratosphere respectively. In conclusion, we have demonstrated that groundbased FTIR measurements are indeed capable of monitoring separately tropospheric ozone from stratospheric ozone with little interferences due to the vertical sensitivity of the retrievals; however, comparison of our results with other independent data sets would be highly desirable in the future.

\section{Comparison of tropospheric ozone from OASIS, IASI, local in-situ measurements and predictions from a regional air-quality model (CHIMERE)}

\subsection{Comparison of OASIS and IASI data}

The IASI instrument (Clerbaux et al., 2007, 2009), launched in October 2006 onboard the satellite MetOp-A, measures the thermal infrared radiation emitted by the Earth's surface and the atmosphere in Nadir geometry. It is a Michelson-type Fourier-transform spectrometer, with a spectral resolution of $0.5 \mathrm{~cm}^{-1}$ (after Gaussian apodisation). The $\mathrm{O}_{3}$ retrievals are performed between 975 and $1100 \mathrm{~cm}^{-1}$ using the same regularization method as for the OASIS spectra. The spectroscopic parameters are taken from HITRAN 2004 (Rothman et al., 2005). More details about the IASI inversions are given in (Eremenko et al., 2008). The capabilities of IASI to monitor total and tropospheric ozone have been demonstrated previously (Eremenko et al., 2008; Keim et al., 2009; Dufour et al., 2010; Viatte et al., 2011). However, IASI has improved sensitivity to lower atmospheric layers under conditions of higher surface temperatures and larger thermal contrast conditions (Eremenko et al., 2008). This is why the comparisons in this paper focus on 25 days of measurements acquired during summer 2009. Figure 4 (upper plot) shows the time series of $\mathrm{O}_{3}$ total columns retrieved by IASI (blue symbols) and OASIS (pink symbols) and the relative differences (gray symbols). Relative differences were calculated as follows:

[(tropospheric $\mathrm{O}_{3} \mathrm{IASI}$ - tropospheric $\mathrm{O}_{3}$ OASIS) /

$$
\text { tropospheric } \left.\mathrm{O}_{3} \text { OASIS }\right] \times 100
$$

The mean relative difference, for 25 coincidences, between tropospheric ozone columns derived from OASIS and IASI, is $-5.6( \pm 16.1) \%$ showing good agreement between those two sets of data. One can note that the total estimated uncertainty for the $0-8 \mathrm{~km}$ ozone partial columns from IASI is about $15 \%$ (Eremenko et al., 2008). Therefore, the mean relative difference does not exceed the estimated uncertainties and thus shows a very good agreement between tropo-
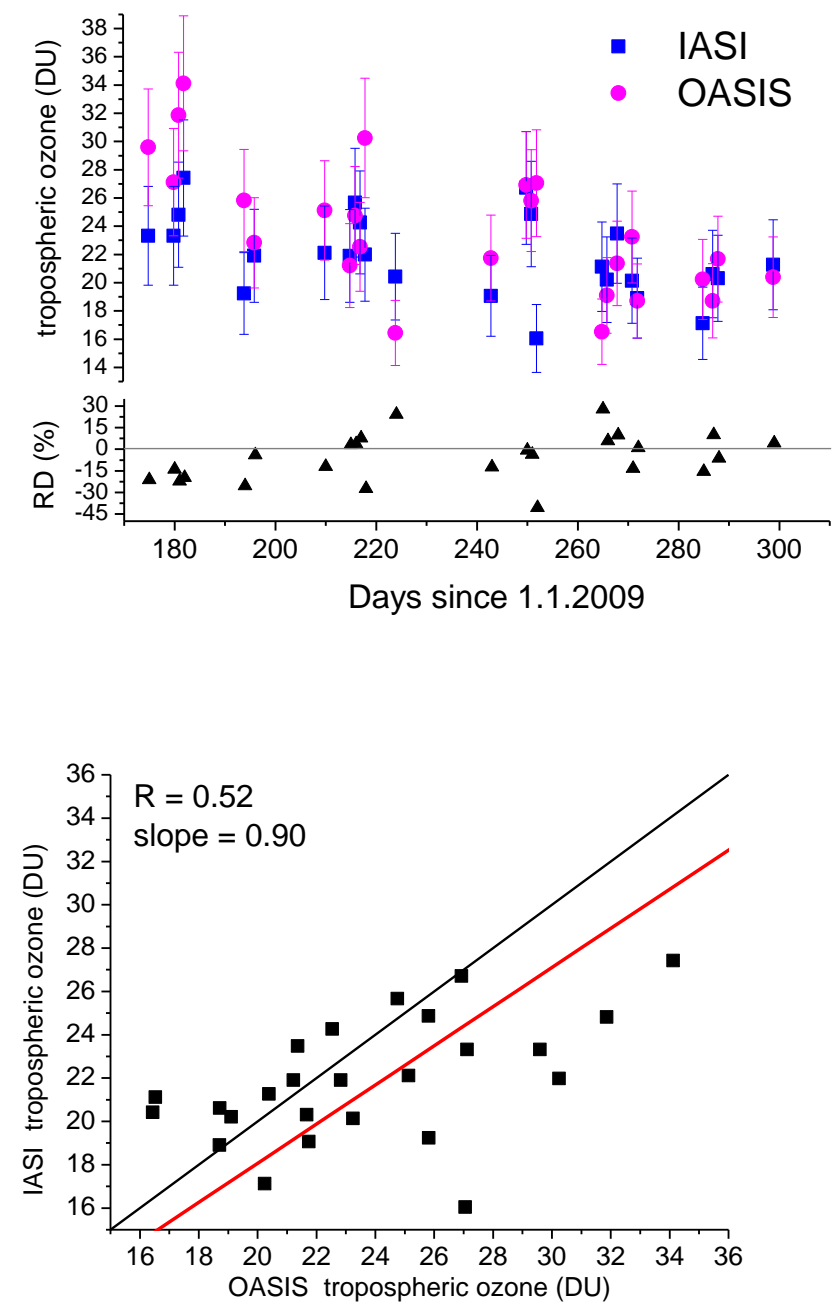

Fig. 4. Upper plot: times series of tropospheric ozone columns derived from IASI (blue squares) and OASIS (pink circles). Error bars related to OASIS and IASI tropospheric ozone uncertainties are indicated. Relative differences (RD) in \% (black triangles) are also indicated. Lower plot: tropospheric $\mathrm{O}_{3}$ columns derived from IASI measurements as a function of OASIS data. Red line is a linear fit with zero intercept.

spheric ozone columns derived from IASI and from OASIS. Figure 4 (lower panel) presents a regression plot of IASI partial columns against OASIS measurements. A linear fit passing through the origin has been used. The correlation coefficient and the slope of linear fitting are 0.52 and 0.90 , respectively. These results confirm the rather good agreement between IASI and OASIS tropospheric ozone measurements. However it must be acknowledged that the different IASI and OASIS averaging kernels (Fig. 2), which reflect differing physics, vertical sensitivities, geometry, and analysis methods, only allow us to draw qualitative conclusions from the comparison, before employing further quantitative analysis, for example with the techniques described in Rodgers and Connor, 2003. 


\subsection{Comparison of OASIS and in-situ data}

In order to verify the quality of tropospheric ozone data derived from OASIS, we qualitatively compared the OASIS time series with in-situ data delivered by the AirParif surface measurements network. Indeed, Fig. 2 shows that OASIS ozone retrievals are strongly sensitive to variability of the lower atmospheric layers. The AirParif network was created in 1979 and approved by the Ministry of Environment to monitor air quality over Paris by analyzing major pollutants (such as ozone, $\mathrm{CO}, \mathrm{NO}_{\mathrm{x}}, \ldots$ ) in various locations of Ile-deFrance, today consisting of 68 stations. Concerning the comparison of OASIS ozone data, we selected the nearest station, located at about $10 \mathrm{~km}$ from the observatory, in Champignysur-Marne. Figure 5 shows the time series of daily tropospheric ozone columns derived from OASIS (black symbols) and in-situ measurements of $\mathrm{O}_{3}$ provided by AirParif (red symbols) for the 75 days of clear-sky OASIS measurements (25 February 2009 to 28 May 2010). In this figure, one can see that seasonal variations of tropospheric ozone are well represented in both curves: increasing ozone during spring (from days 70 to 180 and from days 420 to the end) and decreasing ozone during fall (from days 250 to 350 ). The maximum amounts of ozone observed in late spring and summer are due to the increase of photochemical production (Penkett et al., 1993). The overall agreement in the shape of these two time series confirms qualitatively that OASIS measurements are able to reproduce tropospheric ozone seasonal variability over Créteil. In addition, two sharp maxima, corresponding to 1 July and 6 August 2009, are observed by OASIS and also in the in-situ data (green arrows). The 1 July corresponds to a pollution episode over Paris, already identified in frame of the Megapoli campaign ("Megacities: Emissions, urban, regional and Global Atmospheric POLlution and climate effects, and Integrated tools for assessment and mitigation", see http://megapoli.dmi.dk/) in which several instruments (LIDAR, in-situ, FTIR ...) onboard various platforms (ground-based, plane) were deployed all around Paris. This result also confirms that OASIS is able to monitor high pollution episodes. In the next section, OASIS data from these two pollution episodes are quantitatively compared with predictions from a regional air-quality model (CHIMERE).

\subsection{Comparison of OASIS measurements and forecast from the atmospheric model CHIMERE}

CHIMERE is a state-of-the-art tropospheric chemistrytransport model (Schmidt et al., 2001). Performances of this model have been widely evaluated (Honoré et al., 2008; de Fouquet et al., 2011) and it is now used for European operational forecast of several trace gases including ozone and particulate matter within the Prev'air platform (http://www. prevair.org/). In the framework of the MACC project (http: //www.gmes-atmosphere.eu/), the model has been run for the summer 2009 on the GEMS domain $\left(-15^{\circ}, 35^{\circ} \mathrm{E} ; 35^{\circ}\right.$,

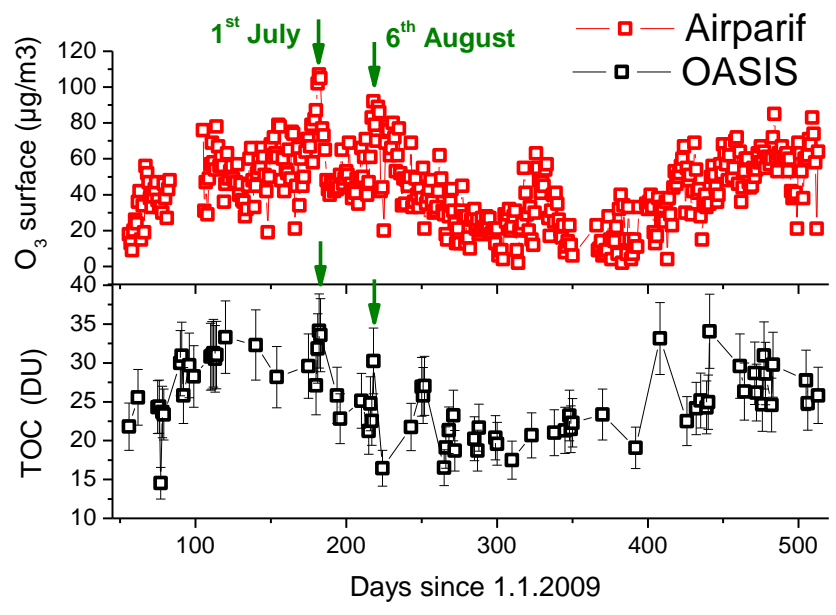

Fig. 5. Times series of tropospheric ozone (tropospheric ozone columns, TOC) from OASIS (black symbols) and surface concentrations from in-situ measurements of the AirParif network (red symbols).

$70^{\circ} \mathrm{N}$ ) with horizontal resolution of $0.25^{\circ} \times 0.25^{\circ}$. Primary pollutant emission profiles are derived from the TNO (http: //www.tno.nl/) inventory re-gridded at the CHIMERE domain resolution. Meteorological conditions (pressure, temperature, wind components, relative humidity, liquid water content and precipitation) are taken from the Integrated Forecasting System (IFS) of the European Centre for MediumRange Weather Forecasts (ECMWF): analyses at 00:00 UT and 12:00 UT are used and complemented with 3-hourly forecasts. We use boundary conditions simulated by the MOZART-3 (Kinnison et al., 2007) model coupled to the IFS (Flemming et al., 2009) using three-hourly reactive gas fields interpolated on an hourly basis. In order to compare tropospheric ozone (and $\mathrm{NO}_{2}$ ) derived from satellite retrievals and CHIMERE simulations, the vertical extension of the model has been extended up to $200 \mathrm{hPa}$ (Eremenko et al., 2008; Huijnen et al., 2010). The vertical grid is discretized in 17 levels, following a hybrid $(\sigma, p)$ scheme; their thickness varies from $50 \mathrm{~m}$ in the surface layer to about $1 \mathrm{~km}$ in the free troposphere.

Concerning coincidence criteria, hourly ozone outputs fields from CHIMERE are spatially interpolated on the OASIS tropospheric grid (from 0 to $12 \mathrm{~km}$ height), and OASIS data are temporally interpolated (within one hour). With these criteria, 33 hourly mean data were compared between OASIS measurements and CHIMERE simulations. Averaging kernels are applied to the CHIMERE profiles to remove the dependency of the comparison on the a-priori $\mathrm{O}_{3}$ profile information used in the retrieval (Rodgers and Connor, 2003). The vertical profiles (from 0 to $8 \mathrm{~km}, 15$ verticals levels) obtained from CHIMERE smoothed by the averaging kernels from OASIS have been calculated for all available OASIS data. Then ozone partial columns were calculated 

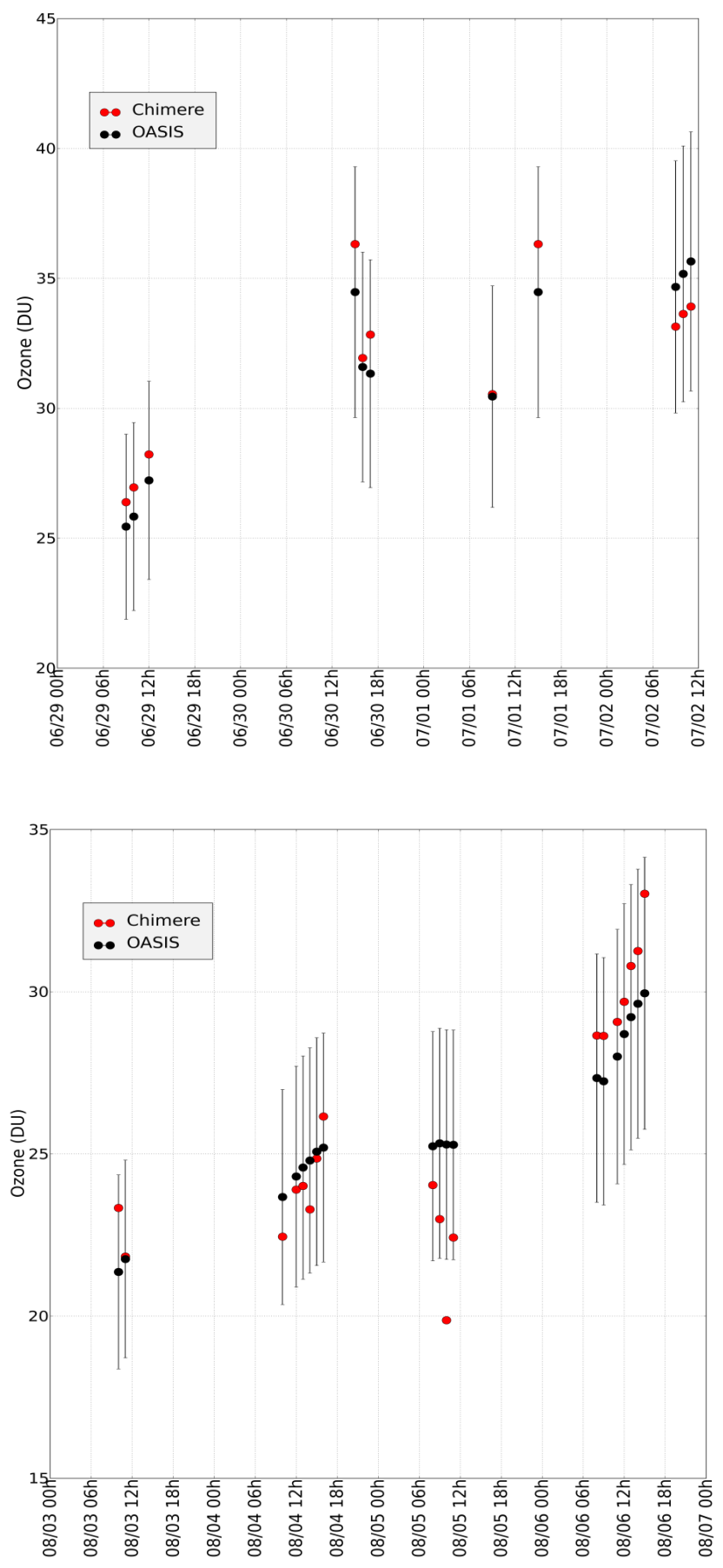

Fig. 6. Time series of tropospheric ozone columns (DU, 0-8 km) derived from OASIS (black dots) and CHIMERE (red dots) for a four days pollution episode: from 06/29 to 07/02 (upper plot) and from 08/03 to 08/06 (lower plot).

from OASIS profiles and CHIMERE profiles smoothed by OASIS averaging kernels. We focus here on the potential of the OASIS measurements to observe tropospheric ozone which is more prominent for two pollution episodes (i.e. from 24 June to 2 July 2009 and from 29 July to
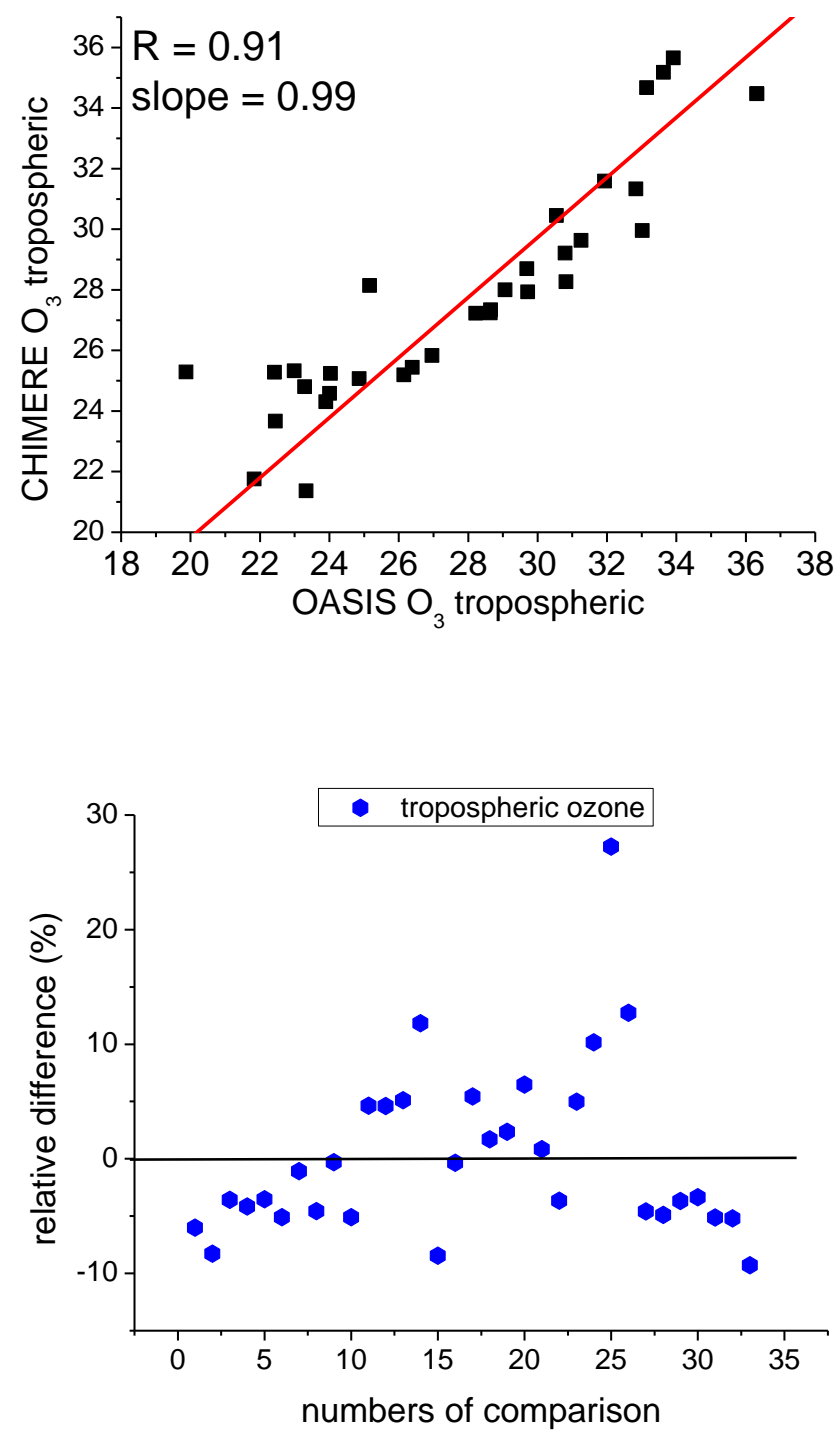

Fig. 7. Upper plot: tropospheric ozone derived from CHIMERE model as a function of tropospheric ozone derived from OASIS measurements. Red line is a linear fit with zero intercept. Lower plot: relative differences (in \%) between CHIMERE and OASIS tropospheric ozone columns for all the 33 hourly mean data involved in the comparison.

6 August 2009). In the Fig. 6, which presents OASIS and CHIMERE tropospheric ozone time series for the first (upper panel) and the second pollution episode (lower panel), one can see that the variability in tropospheric ozone is well captured by both data sets. Figure 7 (upper panel) shows CHIMERE partial columns as a function of tropospheric ozone derived from OASIS measurements for 33 hourly mean data involved in the comparison. A linear fit passing through the origin is used. The correlation coefficient of 0.91 shows very good agreement between CHIMERE and OASIS tropospheric ozone columns. In addition, the slope of linear fitting of 0.99 confirms this excellent correlation. 
Figure 7 (lower panel) represents relative differences in \% between these two set of tropospheric ozone partial columns for all the 33 hourly mean data of the comparison. Mean differences between these two partial columns were calculated using this equation:

$$
\begin{aligned}
& {\left[\left(\text { tropospheric } \mathrm{O}_{3} \mathrm{CHIMERE}\right)-\left(\text { troposphericO }_{3} \mathrm{OASIS}\right) /\right.} \\
& \left.\left(\text { tropospheric } \mathrm{O}_{3} \mathrm{OASIS}\right)\right] \times 100
\end{aligned}
$$

One can see on this figure that differences range from $-10 \%$ to $+15 \%$ (except for one point), that do not exceed the error uncertainties. These results show also excellent agreements, with an average bias of $0.2 \%$, and a standard deviation $(1 \sigma)$ of $7.6 \%$. The mean relative difference (MRD) is extremely low and the dispersion around this average does not exceed the error estimation.

In conclusion, this comparison shows good agreement between tropospheric ozone from OASIS measurements and from the regional air-quality model CHIMERE for two summer pollution episodes over Paris.

\section{Conclusions}

From this first analysis of information content in OASIS ozone retrievals, it is clear that tropospheric ozone can be monitored separately from stratospheric ozone since degrees of freedom reach unity in those two partial atmospheric layers.

We also show that OASIS and IASI tropospheric ozone columns are in good agreement for comparisons under summer conditions (warm surface temperature, high thermal contrast), since the mean relative difference between these two times series is $-5.6( \pm 16.1) \%$ during summer 2009. Remaining differences are probably due to different vertical sensitivities and sampling geometry and volumes, as expected.

In addition, good agreement is also observed when comparing OASIS tropospheric ozone columns with in-situ surface data from the AirParif network: the seasonal tropospheric variation is well reproduced and two episodes of strong ozone pollution (i.e. 1 July and 6 August 2009) are observed by OASIS.

Finally, when comparing OASIS tropospheric ozone columns with the regional air-quality model CHIMERE around these two pollution events, an excellent agreement of $0.2( \pm 7.6) \%$ is observed, and a correlation coefficient of 0.91 , with a slope of 0.99 , between CHIMERE and OASIS data confirms this observation.

In conclusion, we have demonstrated that the new solar absorption ground-based observatory (OASIS) equipped with a medium-resolution infrared Fourier-transform spectrometer is able to continuously monitor tropospheric ozone over Créteil with good accuracy. Given the moderate costs and the compactness of such systems, deployment at larger scale, and particularly at missing atmospheric measurements regions, might be envisaged in support of satellite validation and air quality studies.

Acknowledgements. The authors wish to thank AirParif for in-situ data, the NASA Goddard Space Flight Center for providing the temperature and pressure profiles of the National Centers for Environmental Prediction (NCEP). The ETHER French atmospheric database (http://ether.ipsl.jussieu.fr) is acknowledged for providing the IASI data. We are also grateful to European Centre for Medium-Range Weather Forecasts (ECMWF), Global Monitoring for Environment and Security (GMES) and the Monitoring of the Atmospheric Composition and Climate (MACC) project for supplying data.

Edited by: H. Worden

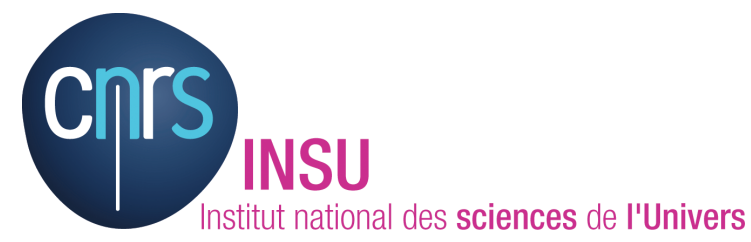

The publication of this article is financed by CNRS-INSU.

\section{References}

Beekmann, M., Ancellet, G., Martin, D., Abonnel, C., Duverneuil, G., Eideliman, F., Bessemoulin, P., Fritz, N., and Gizard, E.: Intercomparison of tropospheric ozone profiles obtained by electrochemical sondes, a ground based lidar and an airborne UV-photometer, Atmos. Environ., 29, 1027-1042, doi:10.1016/1352-2310(94)00336-J, 1995.

Clerbaux, C., Hadji-Lazaro, J., Turquety, S., George, M., Coheur, P.-F., Hurtmans, D., Wespes, C., Herbin, H., Blumstein, D., Tournier, B., and Phulpin, T.: The IASI/MetOp Mission: First Observations and Highlights of its Potential Contribution to GMES, COSPAR Inf. Bul., 19-24, 2007.

Clerbaux, C., Boynard, A., Clarisse, L., George, M., Hadji-Lazaro, J., Herbin, H., Hurtmans, D., Pommier, M., Razavi, A., Turquety, S., Wespes, C., and Coheur, P.-F.: Monitoring of atmospheric composition using the thermal infrared IASI/MetOp sounder, Atmos. Chem. Phys., 9, 6041-6054, doi:10.5194/acp-9-6041-2009, 2009.

Dufour, G., Eremenko, M., Orphal, J., and Flaud, J.-M.: IASI observations of seasonal and day-to-day variations of tropospheric ozone over three highly populated areas of China: Beijing, Shanghai, and Hong Kong, Atmos. Chem. Phys., 10, 3787-3801, doi:10.5194/acp-10-3787-2010, 2010.

Eremenko, M., Dufour, G., Foret, G., Keim, C., Orphal, J., Beekmann, M., Bergametti, G., and Flaud, J.-M.: Tropospheric ozone distributions over Europe during the heat wave in July 2007 observed from infrared nadir spectra recorded by IASI, Geophys. Res. Lett., 35, L18805, doi:10.1029/2008GL034803, 2008.

Flemming, J., Inness, A., Flentje, H., Huijnen, V., Moinat, P., Schultz, M. G., and Stein, O.: Coupling global chemistry transport models to ECMWF's integrated forecast system, Geosci. Model Dev., 2, 253-265, doi:10.5194/gmd-2-253-2009, 2009. 
de Fouquet, C., Malherbe, L., and Ung, A.: Geostatistical analysis of the temporal variability of ozone concentrations. Comparison between CHIMERE model and surface observations, Atmos. Environ., 45, 3434-3446, doi:10.1016/j.atmosenv.2011.03.036, 2011.

Hase, F., Hannigan, J. W., Coffey, M. T., Goldman, A., Höpfner, M., Jones N. B., Rinsland, C. P., and Wood, S. W.: Intercomparison of retrieval codes used for the analysis of high-resolution, ground-based FTIR measurements, J. Quant. Spectrosc. Rad. Transf., 87, 25-52, 2004.

Holton, J. R., Haynes, P. H., McIntyre, M. E., Douglass, A. R., Rood, R. B., and Pfister, L.: Stratosphere-troposphere exchange, Rev. Geophys., 33, 403-439, 1995.

Honoré, C., Rouïl, L., Vautard, R., Beekmann, M., Bessagnet, B., Dufour, A., Elichegaray, C., Flaud, J.-M., Malherbe, L., Meleux, F., Menut, L., Martin, D., Peuch, A., Peuch, V.-H., and Poisson N.: Predictability of European air quality: Assessment of 3 years of operational forecasts and analyses by the PREV'AIR system, J. Geophy. Res., 113, D04301, doi:10.1029/2007JD008761, 2008.

Huijnen, V., Eskes, H. J., Poupkou, A., Elbern, H., Boersma, K. F., Foret, G., Sofiev, M., Valdebenito, A., Flemming, J., Stein, O., Gross, A., Robertson, L., D'Isidoro, M., Kioutsioukis, I., Friese, E., Amstrup, B., Bergstrom, R., Strunk, A., Vira, J., Zyryanov, D., Maurizi, A., Melas, D., Peuch, V.-H., and Zerefos, C.: Comparison of $\mathrm{OMI} \mathrm{NO}_{2}$ tropospheric columns with an ensemble of global and European regional air quality models, Atmos. Chem. Phys., 10, 3273-3296, doi:10.5194/acp-10-3273-2010, 2010.

IPCC: Climate Change 2007: The Physical Science Basis, edited by: Solomon, S., Quin, D., Manning, M., Chen, Z., Marquis, M., Averyt, K. B., Tignor, M., and Miller, H. L., Cambridge University Press, Cambridge, United Kingdom et New York, NY, USA, 2007.

Keim, C., Eremenko, M., Orphal, J., Dufour, G., Flaud, J.-M., Höpfner, M., Boynard, A., Clerbaux, C., Payan, S., Coheur, P.F., Hurtmans, D., Claude, H., Dier, H., Johnson, B., Kelder, H., Kivi, R., Koide, T., López Bartolomé, M., Lambkin, K., Moore, D., Schmidlin, F. J., and Stübi, R.: Tropospheric ozone from IASI: comparison of different inversion algorithms and validation with ozone sondes in the northern middle latitudes, Atmos. Chem. Phys., 9, 9329-9347, doi:10.5194/acp-9-9329-2009, 2009.

Kinnison, D., Barsseur, G., Walters, S., Garcia, R., Marsh, D., Sassi, F., Harvey, V., Randall, C., Emmons, L., Lamarque, J., Hess, P., Orlando, J., Tie, X., Randel,W., Pan, L., Gettelman, A., Granier, C., Diehl, T., Niemeier, U., and Simmons, A.: Sensitivity of chemical tracers to meteorological parameters in the MOZART-3 chemical transport model, J. Geophys. Res., 112, D20302, doi:10.1029/2006JD007879, 2007.

McPeters, R. D., Kroon, M., Labow, G., Brinksma, E. J., Balis, D., Petropavlovskikh, I., Veefkind, J. P., Bhartia, P. K., and Levelt, P. F.: Validation of the Aura Ozone Monitoring Instrument Total Column Ozone Product, J. Geophys. Res., 113, doi:10.1029/2007JD008802, 2008.

Penkett, S. A., Blake, N. J., Lightmann, P., Mardr, A. R. W., Ancoyl, P., and Butcher, G.:The seasonal variation of non methane hydrocarbons in the free troposphere over the North Atlantic Ocean: possible evidence for extensive reaction of hydrocarbons with the nitrate radical, J. Geophys. Res., 98, 2865-2885, 1993.
Pougatchev, N. S., Connor, B. J., Jones, N. B., and Rinsland, C. P.: Validation of ozone profile retrievals from infrared ground-based solar spectra, Geophys. Res. Lett., 23, 1637-1640, 1996.

Rodgers, C. D.: Inverse Methods for Atmospheric Sounding: Theory and Practice, 200pp., World Sci., Hackensack, N. J., 2000.

Rodgers, C. D. and Connor, B. J.: Intercomparison of remote sounding instruments, J. Geophys. Res., 108, 4116, doi:10.1029/2002JD002299, 2003.

Rothman, L. S., Jacquemart, D., Barbe, A., Chris Benner, D., Birk, M., Brown, L. R., Carleer, M. R., Chackerian, C., Chance, K. L., Coudert, L. H., Dana, V., Devi, V. M., Flaud, J.-M., Gamache, R. R., Goldman, A., Hartmann, J.-M., Jucks, K. W., Maki, A. G., Mandin, J. -Y., Massie, S. T., Orphal, J., Perrin, A., Rinsland, C. P., Smith, M. A. H., Tennyson, J., Tolchenov, R. N., Toth, R. A., Vander Auwera, J., Varanasi, P., and Wagner, G.: The HITRAN 2004 molecular spectroscopic database, J. Quant. Spectrosc. Radiat. Transf., 96, 139-204, 2005.

Schmidt, H., Derognat, C., Vautard, R., and Beekmann, M.: A comparison of simulated and observed ozone mixing ratios for the summer of 1998 in western Europe, Atmos. Environ., 35, 62776297, 2001.

Schneider, M., Blumenstock, T., Hase, F., Höpfner, M., Cuevas, E., Redondas, A., and Sancho, J. M.: Ozone profiles and total column amounts derived at Izaña Tenerife Island, from FTIR solar absorption spectra, and its validation by an intercomparison to ECC-sonde and Brewer spectrometer measurements, J. Quant. Spectrosc. Rad. Transf., 91, 245-274, 2005.

Schneider, M., Hase, F., and Blumenstock, T.: Water vapour profiles by ground-based FTIR spectroscopy: study for an optimised retrieval and its validation, Atmos. Chem. Phys., 6, 811-830, doi:10.5194/acp-6-811-2006, 2006.

Schneider, M., Hase, F., Blumenstock, T., Redondas, A., and Cuevas, E.: Quality assessment of $\mathrm{O}_{3}$ profiles measured by a state-of-the-art ground-based FTIR observing system, Atmos. Chem. Phys., 8, 5579-5588, doi:10.5194/acp-8-5579-2008, 2008.

Tikhonov, A. N.: Solution of incorrectly formulated problems and the regularization method, Soviet Math Dokl 4, 1035-1038 English translation of Dokl Akad Nauk SSSR 151, 501-504, 1963.

Viatte, C., Schneider, M., Redondas, A., Hase, F., Eremenko, M., Chelin, P., Flaud, J.-M., Blumenstock, T., and Orphal, J.: Comparison of ground-based FTIR and Brewer $\mathrm{O}_{3}$ total column with data from two different IASI algorithms and from OMI and GOME-2 satellite instruments, Atmos. Meas. Tech., 4, 535-546, doi:10.5194/amt-4-535-2011, 2011.

Vigouroux, C., De Mazière, M., Demoulin, P., Servais, C., Hase, F., Blumenstock, T., Kramer, I., Schneider, M., Mellqvist, J., Strandberg, A., Velazco, V., Notholt, J., Sussmann, R., Stremme, W., Rockmann, A., Gardiner, T., Coleman, M., and Woods, P.: Evaluation of tropospheric and stratospheric ozone trends over Western Europe from ground-based FTIR network observations, Atmos. Chem. Phys., 8, 6865-6886, doi:10.5194/acp-8-68652008, 2008. 